\title{
Modified Negative Pressure Wound Therapy (Modified NPWT): An experience of 128 cases
}

\author{
Ranjeet $N,,^{*} D y A U . J r^{2}$ \\ ${ }^{1}$ Department of Orthopedics, Manipal Teaching Hospital, Pokhara, Nepal, \\ ${ }^{2}$ Department of Orthopedics, Philippine General Hospital, Philippines
}

\section{*Corresponding Author: \\ Dr. Niraj Ranjeet \\ Lecturer, Department of Orthopedics \\ Manipal Teaching Hospital, Pokhara, Nepal \\ Email: ranjitniraj@yahoo.com}

\section{Citation}

Ranjeet N, Dy AU. Jr. Modified Negative Pressure Wound Therapy (Modified NPWT): An experience of 128 cases. Nepal Journal of Medical sciences 2012;1(2):108-14.

\begin{abstract}
Background: Negative Pressure Wound Therapy (NPWT) or Vacuum Assisted Closure (VAC) is a method used to cover large wounds, decubitus ulcers and open fractures which cannot be closed either primarily or secondarily and which often requires skin graft or flaps or complex reconstructive procedure to cover the wound.
\end{abstract}

Methods: We applied our modification of NPWT in 128 patients on large wounds, neglected wounds, large decubitus ulcers, fasciotomies and open fractures. Compared to the patented VAC system, our modification included presterilized foam, Saran ${ }^{\circledR}$ wrap or Glad ${ }^{\circledR}$ wrap, infant feeding tube or a nasogastric tube and bed side suction machine.

Results: Majority of our cases were from open fractures. There were 98 cases of large soft tissue wounds, 3 cases of fasciotomies for compartment syndrome, 7 cases of peri-operative trauma infections, 16 cases of diabetic wounds and 4 decubitus ulcers. In our study, the average number of modified NPWT changes is 3 to 4 , average number of days between modified NPWT changes is 3 to 5 days, and length of time modified NPWT applied before closure is 14 to 21 days. Most frequent mode of coverage is Split Thickness Skin Graft obviating the need of more complex flaps and microvascular reconstructive procedures.

Conclusion: Our modifications are not inferior to the patented VAC but works just as well. The costs of our modifications are much less than the patented VAC, which is economical for our setting.

Keywords: Negative pressure wound therapy; vacuum assisted closure; wound

So, depending on length of time used and number of dressing change required the total cost may be from 30,000 to 40,000 Nepalese Rupee per patients.

Its main attraction was its portability and comfort to the patient as this machine was quiet and could be operated from any readily available wall socket. Since cost was an issue to our generally poor population and infection control locally a big factor in healing, we decided to collect cases from trauma admissions, formulating a protocol for which all 
large wounds and open fractures with or without an external fixator would be included in this study. We also had referrals with large wounds neglected from the start as well as large decubitus ulcers from prolonged recumbency secondary to spinal cord injuries and a few cases of fasciotomies to which we applied the Modified NPWT.

We modified the portable suction machine using our inhospital bedside suction, hospital wall suction or Gomco ${ }^{\circledR}$ suction machine. Our disposables were made up of Ioban $\mathbb{R}$ (iodine laced barrier drapes) or Saran ${ }^{\circledR}$ wrap, regular packing foam and nagogastric or infant feeding tube gauge 18-25. Saran ${ }^{\circledR}$ wrap and foam were gas sterilized in the hospital. The total cost of our Modified NPWT system ranged from 500-1,000 Nepalese Rupee per patient, which was much too cheap as compared to the original VAC system.

There are currently 2 main theories regarding the mechanism of action of VAC therapy. The first is based on the stimulatory effect of microstrain on cellular mitogenesis, angiogenesis, and elaboration of growth factors. This is the same mechanism that is operational in controlled Ilizarovian distraction or in tissue expansion. The second is based on the enhancement of the dynamics of microcirculation by active evacuation of excess interstitial fluid in the form of edema. ${ }^{1,2}$ vacuum may also alters the micro organisms' capacity to proliferate. Some authors also hypothesize that VAC alters the vascular regulation in underlying tissue. ${ }^{3}$

This report is an accumulation of our Modified NPWT experience from January 2006- February 2012. Only those patients with complete data in our charts were included.

\section{Methods:}

All VACs were applied and changed in a sterile condition in an operating room. The patient was brought to the operating room for debridement of the wound and the affected limb was prepped and draped. A thorough debridement of all devitalized tissues was done. A complete excisional debridement was performed using knife, scissor followed by copious wash. Intraoperative cultures were obtained during the debridement. The wound was then prepared for the application of our modified NPWT.

Pre-sterilised foam was taken and shaped according to the wound to be closed. A tunnel was made at the centre of the foam using a metz scissor. An infant feeding tube or a nasogastric tube was taken and additional holes made by cutting the round tip and along the length of the tube inside the foam. The tube was then embedded inside the foam

tunnel (Figure 1). Sometimes over a graft, vaselinized gauze was applied on the wound and the foam was placed on this wet gauze to decrease chance of adhesions.

A

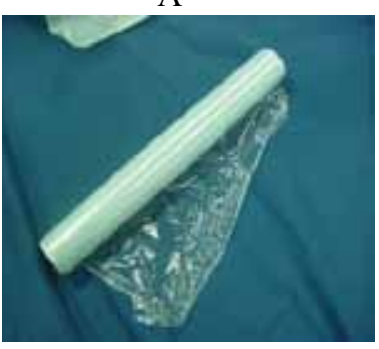

$\mathrm{C}$

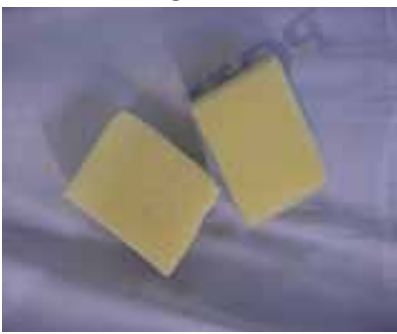

Figure 1: Our components used in VAC. A: Saran ${ }^{\circledR}$ wrap, B: Nasogastric or infant feeding tube gauge 1825, extra holes are made as needed $\mathrm{C}$ : Foam, a tunnel is created at its centre and D: Gomco ${ }^{\circledR}$ suction machine, portable and creates $60-70 \mathrm{mmHg}$ of negative pressure

A pre-sterilized Saran $\AA$ wrap or Glad $\AA$ wrap (Ioban $\AA$, Steridrap ${ }^{\circledR}$ or any brand of barrier drape) was wrapped around the area. The ends of this seal were then obliterated by applying Leukoplast ${ }^{\circledR}$ plaster tapes thus making it an air tight seal (Figure 2).

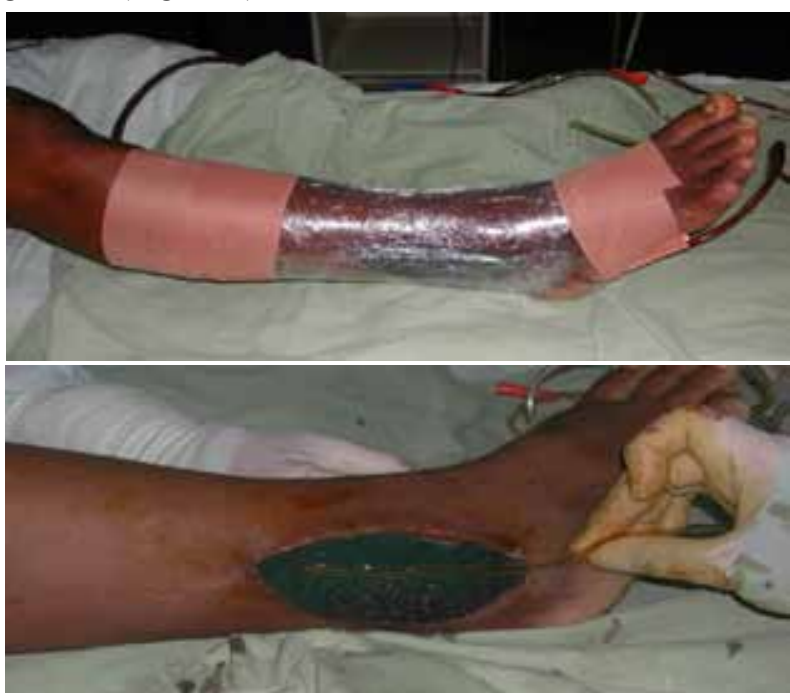

Figure 2: Foam is cut with a metz scissor in the shape of the wound. A Nasogastric tube or an infant feeding tube is placed in a tunnel of the foam. It is then wrapped by Saran ${ }^{\circledR}$ wraps. The edges are obliterated by using Leukoplast ${ }^{\circledR}$ plaster tapes thus making it a sealed dressing 
The tube was then connected to the suction to check if the foam collapses, if not then we looked for any unsealed area then sealed it with more plaster tapes. In cases of external fixators, slit cuts on the Saran ${ }^{\circledR}$ wraps were made to seal pin sites and tapes around the pin sites sealed the area adequately (Figure 3).

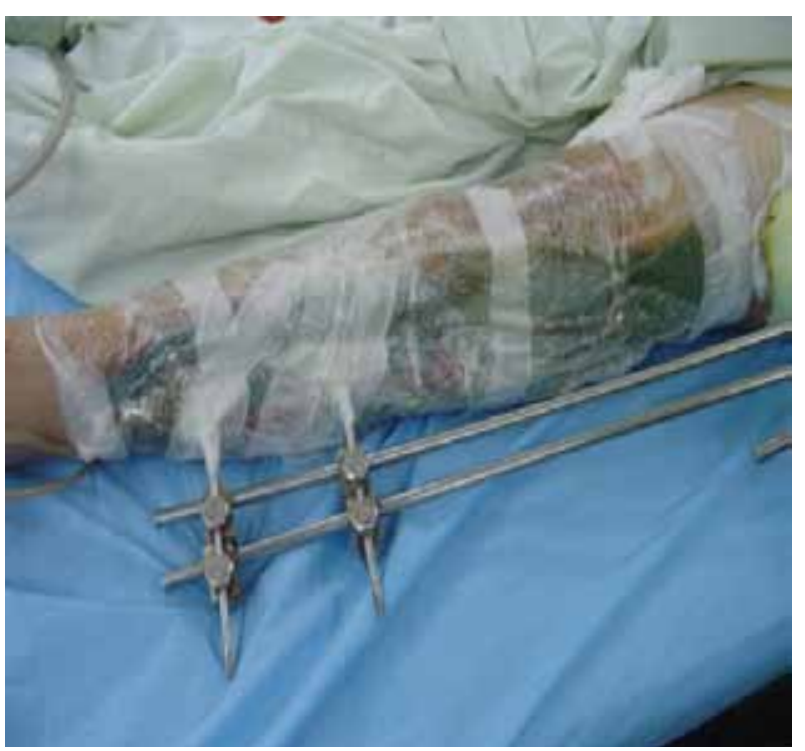

Figure 3: Applying VAC around a external fixator requires an extra effort. The Saran ${ }^{\circledR}$ wrap are slit cut around the pins. Leukoplast ${ }^{\circledR}$ plaster tapes has to be properly applied around the pins so as to make it a sealed dressing.

Around 5 layers of Saran ${ }^{\circledR}$ wrapping was usually adequate to seal the system. Once in the recovery room negative pressure was applied. Suction machine was set to $60-70$ $\mathrm{mmHg}$ of atmospheric pressure turned on for 30-60 minutes and then turned off for the next 30-60 minutes creating an intermittent suction as this was found to be better than continuous suction. ${ }^{4,5}$ Dressing was changed every third to fifth day as there were often delays in our institution in bringing our patients for repeat debridement to the operating room. Once a clean wound bed was obtained, the wound was covered definitively with a split-thickness skin graft or flap as in sacral decubitus ulcers (Figure 4).

\section{Results:}

From January 2006- February 2012,128 patients underwent the modified NPWT procedure. There were 107 males and 21 females. There were 15 pediatric (up to 18 years) (11\%), 109 adult less than 65 years $(85 \%)$ and 4 adult more than 65 years $(3 \%)$. Upper extremity alone was involved in $18 \%$, lower extremity alone in $71 \%$, combined extremity in $6 \%$ and back in $4 \%$ (Table 1 ).

\begin{tabular}{|c|c|c|}
\hline \multirow[t]{3}{*}{ Age, years } & Pediatric & $15(11 \%)$ \\
\hline & Working age $18-65$ & $109(85 \%)$ \\
\hline & Adult beyond 65 & $4 \quad(3 \%)$ \\
\hline \multirow[t]{2}{*}{ Gender } & Male & $107(83 \%)$ \\
\hline & Female & $21(16 \%)$ \\
\hline \multirow[t]{5}{*}{ Types of wound } & Trauma & $98(76 \%)$ \\
\hline & Diabetic wounds/ulcers & $16(12 \%)$ \\
\hline & Peri-operative infection & $7 \quad(5 \%)$ \\
\hline & Decubitus ulcers & $4 \quad(3 \%)$ \\
\hline & Fasciotomy wounds & $3(2 \%)$ \\
\hline \multirow{4}{*}{$\begin{array}{l}\text { Involvement of } \\
\text { area }\end{array}$} & Upper extremity & $23(18 \%)$ \\
\hline & Lower extremity & $91(71 \%)$ \\
\hline & Combined & $8 \quad(6 \%)$ \\
\hline & Back & $6 \quad(4 \%)$ \\
\hline \multirow{4}{*}{$\begin{array}{l}\text { Mechanism of } \\
\text { injury }\end{array}$} & Motorcycle accidents & $23(18 \%)$ \\
\hline & Auto pedestrian accidents & $23(18 \%)$ \\
\hline & Vehicular crash & $26(20 \%)$ \\
\hline & $\begin{array}{l}\text { Others (falls, labor accidents, } \\
\text { mauling, gunshot wounds) }\end{array}$ & $56(43 \%)$ \\
\hline \multirow[t]{2}{*}{ Size of wound } & $<6 \mathrm{~cm}$ & $39(30 \%)$ \\
\hline & $>6 \mathrm{~cm}$ & $89(69 \%)$ \\
\hline Number of VAC & $1-3$ changes & $75(58 \%)$ \\
\hline \multirow[t]{2}{*}{ change } & $4-6$ changes & $45(35 \%)$ \\
\hline & $7-9$ changes & $8 \quad(6 \%)$ \\
\hline Time to consult & $<12$ hours & $80(62 \%)$ \\
\hline \multirow[t]{2}{*}{ since injury } & $12-24$ hours & $33(25 \%)$ \\
\hline & $>24$ hours (1-13 days) & $15(11 \%)$ \\
\hline
\end{tabular}

The majority of cases were from open fractures. 98 cases of large soft tissue wounds with or without external fixator including 3 cases of fasciotomies for compartment syndrome were included. Seven cases of peri-operative trauma infections (qualified as infections as problem within 30 days of operation), 16 cases of diabetic wounds were also included. Four decubitus ulcers with large sacral lesions were also treated with VAC, prior to swinging a V-Y gluteal advancement flap, as a way to control infection and stimulate graft bed (Figure 4). 


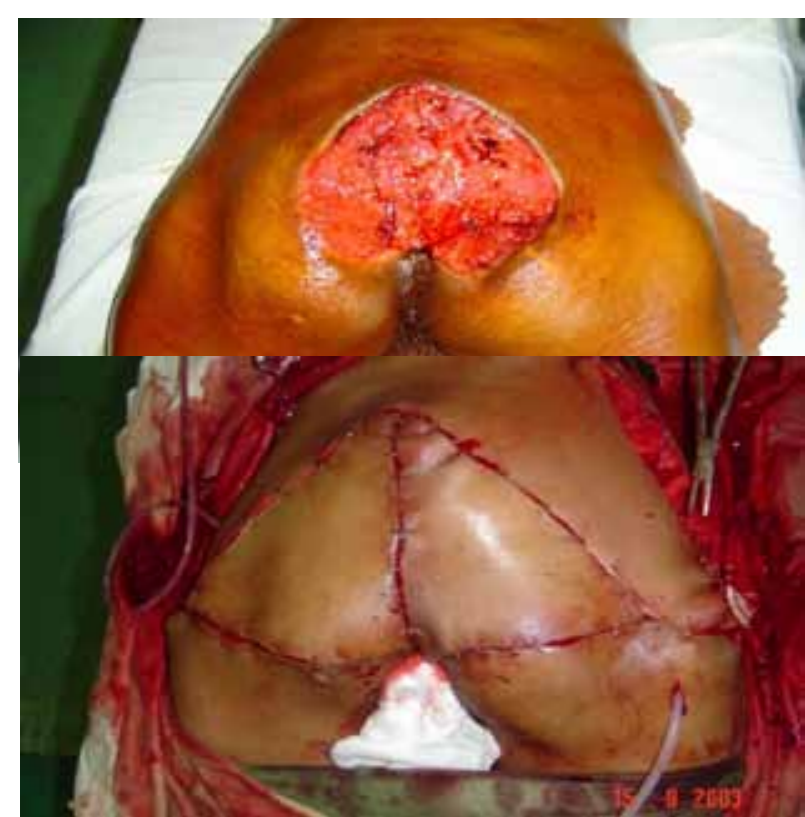

Figure 4: Decubitus ulcer in a 78 year old man. Good granulation tissue bed was achieved after 3 VAC changes. The soft tissue defect was covered using bilateral V-Y Gluteal advancement flaps.

Since infection management was also a purpose of this study, we looked at initial organisms cultured and interestingly found Staphylococcus aureus only three times common. The rest being various gram negative organisms such as Enterobacter, Enterococcus, Klebsiella, Proteus, E. Coli and Pseudomonas. Subsequent culture from repeat debridement yielded only Staphylococcus aureus two times common, rest being gram negative organisms again mostly $E$ Coli, Enterobacter and Pseudomonas, indicating microbacterial flora in our hospital to be predominantly gram negative.

Closures of open fractures were often delayed as they usually come more than 12 hours after injury. Thus during repeat debridement (second look) more necrosis and dead tissues are often found, requiring enlarging the injured area. VAC's advantage is that it causes less tissue loss, decreases bacterial load (wound does not smell and doesn't have discharge) with less oedema overall, helps in controlling tough nosocomial infection. Subsequent debridements show granulation buds which progressively thicken in next changes of dressing.

Our results showed that out of 128 cases the average number of modified NPWT changes was 3 to 4, average number of days between modified NPWT changes 3 to 5 days, length of time modified NPWT applied before closure was 14 to 21 days. Most frequent mode of coverage was Split Thickness Skin Graft (STSG) obviating the need of more complex flaps and microvascular reconstructive procedures.
There were no cases of true failures from modified NPWT. One patient complained of the noise of the suction machine. She was a patient with type II open fractures but with large lacerated wound and requested for earlier discontinuation of modified NPWT.

Another patient had 16 modified NPWT changes before closure with STSG. This was because of poorly nourished, persistently anaemic status and poor antibiotic compliance for his infected wounds. He stayed in the hospital for more than 3 months.

Next patient was an open type III distal femoral fracture with popliteal artery bypass grafting and associated tibia and fibula fracture. Modified NPWT was set up over the external fixator, extremity developed gangrene due to failure of the popliteal artery bypass after 3 weeks. Patient underwent above knee amputation because of the gangrene. Healthy granulation tissue was observed at the open fracture site. This demonstrated the ability of modified NPWT to stimulate regeneration therefore not truly a failure of the procedure (Figure 5).

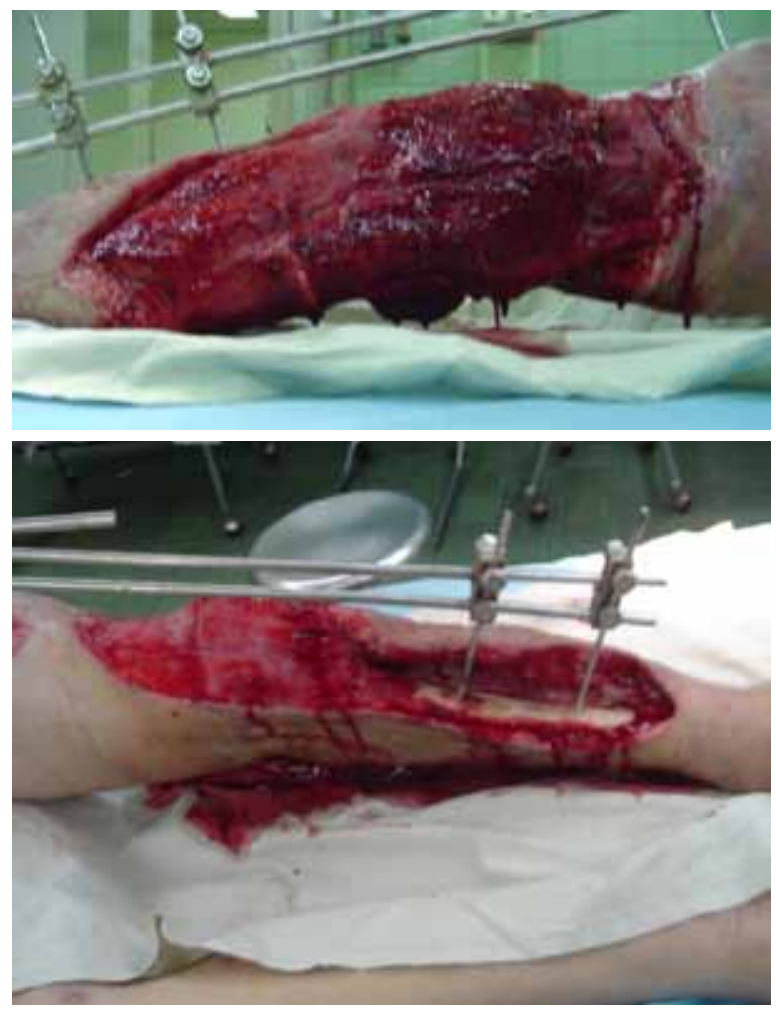

FIGURE 5: Patient with Open III-C Distal Femur Fracture with popliteal artery injury associated with tibia and fibula fracturewho underwent Popliteal Artery Bypass Grafting - note large leg avulsion with exposed tibia. However, it was the Popliteal Artery Bypass Graft that failed at 3 weeks, resulting in amputation.

Three patients with diabetic gangrene with uncontrolled 
blood sugar had to have definitive amputation to control the infections. This demonstrates that poorer vascularity in diabetes may not be good candidates for modified NPWT but this technique can be used to temporize the care of these wounds while optimizing the patients before definitive treatment that is, awaiting wound delineation and control of infection.

\section{Discussion:}

Thorough surgical debridement still remains the primary option for all open wounds without which no other adjunctive procedure will work. VAC just helps us surgeons with the effect of continuous negative pressure on wound healing by removing fluid, increasing circulation, stimulating granulation tissue and regeneration. ${ }^{4-7}$

The basis for VAC is based on various animal and human studies. ${ }^{8,9}$ An ICL lecture on VAC in open tibial fractures in AAOS meeting in 2004 reported 44 patients; randomized to standard wound protocol versus VAC found the following, drainage was lessened with VAC 3.1days versus 1.6days $(\mathrm{p}=.003)$, infection $16 \%$ versus $8 \%$ in patients with VAC. ${ }^{10}$ A study reported $10^{7}$ bacterial count down to $10^{2}-10^{3}$ per gram of tissue at fourth and fifth day with VAC treatment, but emphasized that this does not obviate need for adequate debridement of traumatized soft tissues. Furthermore, it simplified the care of complex soft tissue wounds as it required less dressing change and more complex flaps to cover soft tissues became less frequently used. ${ }^{11}$

A study noted an increased tissue $\mathrm{O}_{2}$ perfusion using $125 \mathrm{mmHg}$ a few $\mathrm{cm}$ from wound edge but included hypoperfusion in immediate vicinity to wound edge thus intermittent makes more sense in that ebb-flow mechanism allows recovery and recommended 75 to $100 \mathrm{mmHg}$ as optimum. ${ }^{12}$ In our study we used 60 to $70 \mathrm{mmHg}$ and found no negative effect of VAC with this pressure setting, furthermore patients are generally comfortable and did not report any pain while the suction was on.

Recent literature has favoured the use of VAC for patients with open infected wounds. ${ }^{13}$ They have used the VAC to decrease the size of traumatic wounds in 21 patients with high-energy soft tissue injuries. In selected patients, they were able to preclude free tissue transfer with VAC or regional muscle transfer. They describe using the VAC to assist wound closure in 75 patients with severe lower extremity wounds with exposed bone. Our experience also confirmed the usefulness of this technique.

VAC was used in 77 Iraqi patients who sustained 88 wounds secondary to missile injuries, in conjunction with repeated irrigation and debridement. They reported decreased hospital stay, simplified ward nursing, ability to effectively use VAC in the field and no infections. ${ }^{14}$

The advantages of VAC was further emphasized by a review article as a method of reducing bacterial counts in wounds, as a bridge until definitive bony coverage, for treating infections, and as an adjunct to wound bed preparation and for bolstering split-thickness skin grafts, dermal replacement grafts, and muscle flaps. ${ }^{15}$ The article states that NPWT has been shown to be an adjunct to the mainstays of wound management. No significant complications have been noted in the categories of NPWT discussed in this review. In addition, evidence supports a decrease in complex soft tissue procedures in grade IIIB open fractures when NPWT is employed. NPWT appears to provide clinical benefit for the treatment of these complex lower extremity wounds. ${ }^{16-18}$

A review of 290 open tibia-fibula fractures Gustilo grade III, from 1992 till 2003, demonstrated a change in practice, with a trend down the reconstructive ladder, currently using fewer free flaps (20\% from 1992-1995, 11\% from 19961999 to $5 \%$ from 2000-2003) and more delayed closures and skin grafts with frequent use of the vacuum-assisted closure sponge which he started using from $1997 .{ }^{19}$

There are two papers which emphasizes statistically significant decrease in median time required to complete healing of acute and chronic wounds. ${ }^{20,21}$ They found a median time to complete healing of 16 days with VAC versus 20 days in the control group $(\mathrm{P}=0.32),{ }^{20}$ and 29 days with VAC versus 45 days in the control group $(\mathrm{P}=0.001){ }^{21}$

Two studies described changes in wound surface area..$^{20,22}$ One study reported a median reduction in wound surface area of $0.3 \mathrm{~cm}^{2}$ per day with VAC versus $0.1 \mathrm{~cm}^{2}$ per day in the control group $\left((\mathrm{P}=0.83) .{ }^{20}\right.$ Where as other reported a reduction in wound surface area in all 15 patients treated with VAC versus 13 of those in a gauze treatment group. ${ }^{22}$ The mean reduction in wound surface area was 3.8 percent per day with VAC compared to 1.7 percent per day with gauze (difference of 2.1 percent per day). Unfortunately in our study, we were not able to measure the surface area and depth of the wound prior to VAC application. Thus, we recommend a prospective study measuring the size and depth of the wound prior to VAC application and measuring the difference in size after VAC application and comparing it to control group.

Some authors reported a median time for the wound bed to be ready for surgery of 7 days with VAC versus 17 days in 
the control group..$^{21,22}$ They reported a median time for the wound bed to be ready for surgery of 6 days for the VAC group versus 7 days for the gauze treated $\operatorname{group}(\mathrm{P}=0.19)$. In our study 14 to 21 days was required before we could definitely close the wound. It may be because of delay in VAC changes that occurs in hospitals because of unavailability of operating room time.

Question if VAC causes anemia is frequently asked however monitoring the VAC drainage over 3 to 5 days does not show appreciable blood losses. Primary cause of the anemia may be debridement with ensuing blood loss.

Thus, our modifications are not inferior to the original VAC but works just as well. The costs of our modifications are much less than the original VAC, which is good for our setting.

\section{Conclusion:}

Our results favour its use over other myofascial flaps as success rates are predictable with this technique. We conclude that our modifications did not show detrimental effects and works as well as the original VAC system. Besides, the components are readily available and it is much cheaper as compared to the original VAC system.

\section{Conflict of interest: none}

\section{References:}

1. Aronson J. Limb-Lengthening, Skeletal Reconstruction, and Bone Transport with the Ilizarov Method. J Bone Joint Surg Am 1997;79:1243-58.

2. Lawrence XW, Hans CP. Current Thought Regarding the Mechanism of Action of Negative Pressure Wound Therapy with Reticulated Open Cell Foam. J Orthop Trauma 2008;22:135-7.

3. Kilpadi DV, Feeley TD, Kiel JW. V.A.C. Therapy Normalizes Vascular Response of Injured Tissue in Full-Thickness Wounds in Rabbits. Ann Plast Surg 2007;58: 555-60.

4. Clare MP, Fitzgibbons TC, McMullen ST, et al. Experience with the vacuum assisted closure negative pressure technique in the treatment of non-healing diabetic and dysvascular wounds. Foot Ankle Int 2002;23:896-901.

5. Cothren CC, Moore EE, Johnson JL, et al. One hundred percent fascial approximation with sequential abdominal closure of the open abdomen. Am J Surg
$2006 ; 192: 238-42$.

6. Saxena V, Hwang CW, Huang S, et al. Vacuumassisted closure: microdeformations of wounds and cell proliferation. Plast Reconstr Surg 2004;114:1086-96.

7. Scholl L, Chang E, Reitz B, et al. Sternal osteomyelitis: use of vacuum-assisted closure device as an adjunct to definitive closure with sternectomy and muscle flap reconstruction. J Card Surg 2004;19:453-61.

8. Morykwas MJ, Argenta LC, Shelton-Brown EI, et al. Vacuum assisted closure: a new method for wound control and treatment. Animal studies and basic foundation. Ann Plast Surg. 1997;38:553-62.

9. Morykwas MJ, Simpson J, Punger K, et al. Vacuumassisted closure: state of basic research and physiologic function. Plast Reconstr Surg (7 suppl) 2006;17:121-6.

10. Gouler. University of Machigan: ICL lecture on VAC in open tibial fractures in AAOS meeting 2004.

11. DeFranzo AJ, Argenta LC, Marks MW, et al. The use of vacuum-assisted closure therapy for the treatment of lower-extremity wounds with exposed bone. Plast Reconstr Surg 2001;108:1184-91.

12. Wackenfors A, Sjogren J, Gustafsson R, et al. Effects of vacuum-assisted closure therapy on inguinal wound edge microvascular blood flow. Wound Rep Regen. 2004;12:6,600-6.

13. Herscovici D, Sanders RW, Scaduto JM, et al. Vacuumassisted wound closure (VAC Therapy) for the management of patients with high-energy soft tissue injuries. J Orthop Trauma 2003;17:683-8.

14. Leininger BE, Rasmussen TE, Smith DL, et al. Experience with wound VAC and delayed primary closure of contaminated soft tissue injuries in Iraq. J Trauma 2006;61:1207-11.

15. Schlatterer D, Hirshorn K. Negative Pressure Wound Therapy With Reticulated Open Cell Foam-Adjunctive Treatment in the Management of Traumatic Wounds of the Leg: A Review of the Literature. J Orthop Trauma 2008;22:152-60.

16. Pollak AN, McCarthy ML, Burgess AR. Short-term wound complications after application of flaps for coverage of traumatic soft-tissue defects about the tibia. The Lower Extremity Assessment Project (LEAP) Study Group. J Bone Joint Surg Am 2000:82:1681-91. 
17. Preston G. An overview of topical negative pressure therapy in wound care. Nursing Standard 2008;23,7:62-8.

18. Webb LX, Dedmond B, Schlatterer D, et al. The contaminated highenergy open fracture: a protocol to prevent and treat inflammatory mediator storm-induced soft-tissue compartment syndrome (IMSICS). J Am Acad Orthop Surg 2006;14(Suppl):82-6.

19. Parrett BM, Matros E, Pribaz JJ, et al. Lower extremity trauma: trends in the management of soft-tissue reconstruction of open tibia-fibula fractures. Plast Reconstr Surg 2006;117:1315-22.

20. Braakenburg A, Obdeijn MC, Van Rooij IALM, et al. The clinical efficacy and cost effectiveness of the vacuum-assisted closure technique in the management of acute and chronic wounds: a randomized controlled trial. Plast Reconstr Surg 2006;118:390-7.

21. Vuersteak JD, Vainas T, Wuite J, et al. State of the art treatment of chronic leg ulcers: a randomized controlled trial comparing vacuum-assisted closure (VAC) with modern wound dressings. J Vasc Surg 2006;44:1029-37.

22. Moues CM, Vos MC, Van Den Bemd GCM, et al. Bacterial load in relation to vacuum-assisted closure wound therapy: a prospective randomized trial. Wound Rep Regen 2004;12:11-7. 